\title{
Antiphospholipid antibodies detected by line immunoassay differentiate among patients with antiphospholipid syndrome, with infections and asymptomatic carriers
}

Dirk Roggenbuck ${ }^{1,2^{*}}$, Maria Orietta Borghi ${ }^{3,4 \dagger}$, Valentina Somma², Thomas Büttner ${ }^{5}$, Peter Schierack², Katja Hanack ${ }^{6}$, Claudia Grossi ${ }^{4}$, Caterina Bodio ${ }^{3}$, Paolo Macor ${ }^{7}$, Philipp von Landenberg ${ }^{8}$, Francesco Boccellato ${ }^{9}$, Michael Mahler ${ }^{10}$ and Pier Luigi Meroni ${ }^{3,4}$

\begin{abstract}
Background: Antiphospholipid antibodies (aPL) can be detected in asymptomatic carriers and infectious patients. The aim was to investigate whether a novel line immunoassay (LIA) differentiates between antiphospholipid syndrome (APS) and asymptomatic aPL+ carriers or patients with infectious diseases (infectious diseases controls (IDC)).

Methods: Sixty-one patients with APS (56 primary, 22/56 with obstetric events only, and 5 secondary), 146 controls including $24 \mathrm{aPL}+$ asymptomatic carriers and 73 IDC were tested on a novel hydrophobic solid phase coated with cardiolipin $(\mathrm{CL})$, phosphatic acid, phosphatidylcholine, phosphatidylethanolamine, phosphatidylglycerol, phosphatidylinositol, phosphatidylserine, beta2-glycoprotein I ( $32 \mathrm{GPI})$, prothrombin, and annexin V. Samples were also tested by anti-CL and anti- $\beta 2$ GPI ELISAs and for lupus anticoagulant activity. Human monoclonal antibodies (humoAbs) against human $\beta 2 \mathrm{GPI}$ or $\mathrm{PL}$ alone were tested on the same LIA substrates in the absence or presence of human serum, purified human $\beta 2 \mathrm{GPI}$ or after CL-micelle absorption.

Results: Comparison of LIA with the aPL-classification assays revealed good agreement for $\operatorname{lgG} / \mathrm{lgM}$ aß2GPI and $\mathrm{aCL}$. Anti-CL and anti-B2GPI IgG/IgM reactivity assessed by LIA was significantly higher in patients with APS versus healthy controls and IDCs, as detected by ELISA. IgG binding to CL and B2GPI in the LIA was significantly lower in aPL+ carriers and Venereal Disease Research Laboratory test (VDRL) + samples than in patients with APS. HumoAb against domain 1 recognized $\beta 2$ GPI bound to the LIA-matrix and in anionic phospholipid (PL) complexes. Absorption with $\mathrm{CL}$ micelles abolished the reactivity of a PL-specific humoAb but did not affect the binding of anti- $\beta 2$ GPI humoAbs.
\end{abstract}

Conclusions: The LIA and ELISA have good agreement in detecting aPL in APS, but the LIA differentiates patients with APS from infectious patients and asymptomatic carriers, likely through the exposure of domain 1.

Keywords: Antiphospholipid syndrome, Antiphospholipid antibody, Phospholipid binding proteins, Beta2 glycoprotein I, Line immunoassay

\footnotetext{
* Correspondence: dirk.roggenbuck@b-tu.de

${ }^{\dagger}$ Equal contributors

${ }^{1}$ Institute of Biotechnology, Faculty 2, Brandenburg University of Technology

Cottbus-Senftenberg, Großenhainer Str. 57, 01968 Senftenberg, Germany

${ }^{2}$ Research and Development Department, Medipan GmbH, Dahlewitz/Berlin,

Germany

Full list of author information is available at the end of the article
} 


\section{Background}

Antiphospholipid syndrome (APS) represents a chronic disabling systemic autoimmune disorder affecting approximately $1 \%$ of the general population and occurring as the primary disorder or being associated with other systemic autoimmune rheumatic diseases. Clinical manifestations are represented by recurrent arterial/venous thrombosis and/or pregnancy morbidity in the persistent presence of antiphospholipid antibodies (aPL) [1-4].

The current international consensus for the classification of APS values clinical and laboratory criteria equally for the diagnosis of APS [2]. The latter criterion comprises the detection of persistent aPL by solid-phase assays, i.e., IgG and IgM to beta2 - glycoprotein I ( $\beta 2 \mathrm{GPI}$ ) and the cardiolipin (CL)- $32 \mathrm{GPI}$ complex, and by a functional clotting test, i.e., the lupus anticoagulant (LA).

Appropriate aPL analysis, however, still remains a laboratory challenge due to the heterogeneity of aPL and standardization issues for the required ELISA and clotting tests [5-8]. Recent studies suggested that the epitope specificity of anti- $\beta 2$ GPI antibodies may differentiate between anti-domain (D) 1 antibodies that are associated with the manifestations of the syndrome and the anti-D4/5 antibodies, which are not [9]. Apart from $\beta 2 \mathrm{GPI}$, other phospholipid (PL)-binding proteins such as prothrombin (PT), annexin $\mathrm{V}(\mathrm{AnV})$, and high-molecular weight kininogen have been described [10-12]. Furthermore, the relevance of aPL assay techniques involving the interaction of PL-binding proteins like 32 GPI and PT with PLs other than CL, such as phosphatidylserine (PS), is still a matter of debate and not yet included in the classification criteria [13].

For risk stratification in patients with APS, different profiles comprising single, double, and triple positivity of aPL are analyzed. Triple positivity in particular seems to be associated with a higher risk for the appearance of clinical APS manifestations [14]. In this context, LA positivity seems to be the best predictor, whereas medium/high levels of IgG to CL and $\beta 2 \mathrm{GPI}$ are more indicative than low levels thereof and IgM, although it has recently been suggested that the IgM isotype also has predictive value $[14,15]$.

There is growing evidence that aPL are pathogenic, although aPL alone are not sufficient to induce APS, and probably perpetuate APS. A "second hit" is required to support these pathophysiological processes [16]. Factors such as traditional cardiovascular risks (e.g., hypertension, diabetes mellitus, and obesity), acquired thrombotic risks (e.g., smoking, oral contraception, and pregnancy), genetic factors in hypercoagulation (e.g., factor V Leiden or II mutation, deficiency of ATIII, and protein C and S), and probably most important infections can provide the required triggers for a second hit. It is still unknown whether the persistent presence of aPL in asymptomatic carriers means that they have not yet met the right second hit or whether their aPL do not display pathogenic activity. Up to date, however, current techniques included in the classification criteria have not allowed differentiation of aPL in patients with APS and those in asymptomatic aPL-positive $(+)$ carriers.

Novel assay techniques have been proposed for aPL testing, such as chemiluminescence-based methods or fluorescence enzyme immunoassays. Recently, a new technique employing a hydrophobic solid phase for the simultaneous detection of different aPL has been developed [13, 17-20]. Remarkably, aPL detected by such line immunoassays (LIAs) appear to be more closely associated with the APS phenotype than those detected by enzyme-linked immunosorbent assay (ELISA) [18, 21]. We speculated on whether LIAs demonstrating improved performance characteristics in comparison with ELISA can be the first test able to detect aPL assisting in the differentiation of patients with APS from asymptomatic aPL+ carriers and aPL-positive patients with infectious diseases.

\section{Methods}

\section{Patients and controls}

In total, 207 individuals were enrolled into the study, comprising 61 patients with APS diagnosed in accordance with the international APS classification criteria and 146 controls (Table 1). Patients with APS were further classified as having primary APS (PAPS) with arterial and/or venous thrombosis in the absence of any other related disease, obstetric APS (OAPS) with pregnancy-related complications listed in the classification criteria (early pregnancy loss, intrauterine death, premature birth, pre/eclampsia, and intrauterine growth retardation), and secondary APS (SAPS) in which the syndrome occurs alongside another autoimmune disease [2]. Further, we included $24 \mathrm{aPL}+$ individuals with no clinical APS manifestations during at least 3 years of follow up (aPL+ asymptomatic carriers). As disease controls we included 73 patients suffering from infectious diseases (infectious diseases controls (IDC)): 3 of these patients were infected with Epstein-Barr virus, 14 with Toxoplasma gondii, 24 with cytomegalovirus (CMV), 8 with Rubella virus, 1 with hepatitis $C$ and 23 with Treponema pallidum displaying a positive Venereal Disease Research Laboratory test result (VDRL+)). All the patients were attending the outpatient clinic at the Division of Rheumatology of the University of Milan. The study was approved by the local ethical committee (Comitato Etico Milano Area B; 08.07.2014, CSGA-115565) and complies with the World Medical Association Declaration of Helsinki on the ethical conduct of research involving human subjects and/or 
Table 1 Characteristics of 61 patients with antiphospholipid syndrome and 146 controls enrolled in the study

\begin{tabular}{|c|c|c|c|c|}
\hline & Number & Median age, years & Age range, years & Gender f/m \\
\hline PAPS $^{*}$ & 34 & 46 & $21-75$ & $23 / 11$ \\
\hline arterial thrombosis & 23 & 47 & $21-66$ & $15 / 8$ \\
\hline venous thrombosis & 12 & 42 & $28-63$ & $8 / 4$ \\
\hline thrombotic and obstetric manifestations & 5 & 41 & $33-51$ & $5 / 0$ \\
\hline OAPS $^{a}$ & 22 & 39 & $27-62$ & $22 / 0$ \\
\hline early pregnancy loss (<10th week of gestation) & 11 & 38 & $34-45$ & $11 / 0$ \\
\hline intrauterine death (>10th week of gestation) & 14 & 40 & $27-57$ & $14 / 0$ \\
\hline premature birth & 5 & 37 & $33-42$ & $5 / 0$ \\
\hline fetuses with intrauterine growth retardation & 9 & 35 & $27-42$ & $9 / 0$ \\
\hline pre/eclampsia & 6 & 34 & $27-37$ & $6 / 0$ \\
\hline SAPS $^{\mathrm{b}}$ & 5 & 38 & $24-58$ & $4 / 1$ \\
\hline $\mathrm{aPL}+$ & 24 & 42 & $22-71$ & $22 / 2$ \\
\hline IDC & 50 & 35 & $6-86$ & $46 / 4$ \\
\hline VDRL+ & 23 & 36 & $19-58$ & $2 / 21$ \\
\hline $\mathrm{HS}$ & 49 & 37 & $19-68$ & $9 / 40$ \\
\hline
\end{tabular}

PAPS primary antiphospholipid syndrome, OAPS obstetric primary antiphospholipid syndrome, $H S$ healthy subjects, aPL+, anti-phospholipid antibody positive, IDC

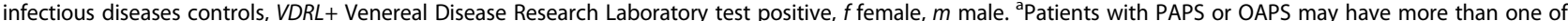

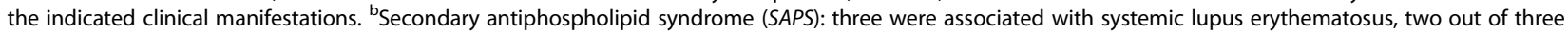
with arterial thrombosis and one with arterial thrombosis and intrauterine death; two were associated with undifferentiated connective tissue disease and with intrauterine deaths

animals. Written informed consent was obtained from each patient. All sera had been stored at $-20{ }^{\circ} \mathrm{C}$.

Sera with APS characterized for reactivity against domain 1 (D1) or domains 4/5 (D4/5) were also included. The domain specificity was carried out by solid-phase assays as previously described [22]. In detail, five patients with APS, who were negative for anti-D1 and positive for anti-D4/5 antibodies, and 9 patients with APS who were positive for anti-D1 and negative for anti-D4/5 antibodies, were analyzed for their reactivity by LIA. The clinical and laboratory features of these patients are reported in Additional file 1: Table S1.

\section{Monoclonal and polyclonal antibodies against PL-binding proteins}

To investigate the interaction with $\beta 2$ GPI in the novel assay environment, we employed the chimeric human monoclonal IgG (humoAb) HCAL, composed of human $\mathrm{k}$ and $\gamma$ constant regions and variable regions from the mouse monoclonal $\beta 2$ GPI-dependent anti-CL antibody (aCL) WBCAL-1 [23]. The humoAb HCAL was from Inova Diagnostics (San Diego, CA, USA). To determine 32 GPI domain reactivity we tested MBB2 - a human minibody containing a single chain fragment variable fused to an IgG1 CH2-CH3-domain that recognizes D1 of human B2GPI [24]. The humoAb RR7F interacting with PL in the ELISA was used to analyze the reactivity to PL immobilized on the hydrophobic membrane employed in LIA [25].
An anti-PT (aPT) moAb (Kerafast, Boston, USA) and an anti-AnV (aAnV) (Cusabio, Wuhan, China) polyclonal antibody were employed to investigate the binding to PT and AnV. To reveal their specific binding, polyclonal anti-mouse and anti-rabbit IgG labeled with peroxidase were used as secondary antibodies, respectively.

\section{Interaction of PL-binding proteins with PL}

The PL-binding proteins, human $\beta 2$ GPI purified from pooled plasma as described elsewhere [26], purified human PT (Arotec Diagnostics, Wellington, New Zeeland), and recombinant human AnV (Diarect, Freiburg, Germany) were used. These PL-binding proteins were investigated for their binding to PL immobilized on the LIA membrane. Ultrapure Bovine Serum Albumin (BSA; Sigma, St Louis, MI, USA), which was free of any $\beta 2$ GPI contamination was used in some experiments.

\section{Inhibition of aPL reactivity by $\mathrm{CL}$ micelles}

For aPL inhibition experiments, CL micelles prepared in a suspension as described elsewhere were employed [27]. Briefly, aß2GPI and aPL humoAbs at a dilution giving positive results in the LIA (1.5 times the cutoff of $50 \mathrm{op}$ tical density units) were incubated with $10 \mathrm{mg} / \mathrm{L} \mathrm{CL}$ micelles in PBS for $1 \mathrm{~h}$ at $37^{\circ} \mathrm{C}$ on a rotator and subsequently overnight at $4{ }^{\circ} \mathrm{C}$. After ultracentrifugation at $16,000 \mathrm{rpm}$ for 45 minutes, the supernatant was collected and the remaining aß2GPI and aPL reactivity determined in the LIA. 


\section{ELISA for the detection of $\mathrm{aCL}$ and aß2GPI}

For the detection of $\mathrm{aCL}$ and $\mathrm{a} 2 \mathrm{GPI}$ in patient sera, commercially available solid-phase ELISAs employing purified human $32 \mathrm{GPI}$ in complex with CL and human ß2GPI were used, respectively (GA Generic Assays $\mathrm{GmbH}$, Dahlewitz, Germany). Sera were considered positive when their concentration exceeded the cutoff of $10 \mathrm{U} / \mathrm{mL}$ for IgG and IgM, respectively. All samples have been tested by respective in-house assays as described elsewhere [22]. The results for the two techniques were comparable (data not shown).

\section{LIA for the detection of aPL}

Antibodies against CL, phosphatidic acid (aPA), phosphatidylcholine (aPC), phosphatidylethanolamine (aPE), phosphatidylglycerol (aPG), phosphatidylinositol (aPI), PS (aPS) and the PL-binding proteins ß2GPI, AnV, and PT were detected in patient sera simultaneously using a commercially available LIA in accordance with the recommendations of the manufacturer (GA) [17]. Briefly, CL, PA, PC, PE, PG, PI, PS, and B2GPI, AnV and PT were sprayed onto a polyvinylidene difluoride (PVDF) membrane in lines for immobilization as described for glycolipids [28]. A mixture of human IgG and IgM was immobilized likewise as the reaction control band.

Serum samples were diluted 1 in $33(30 \mu \mathrm{L}+1 \mathrm{~mL})$ and incubated for 30 minutes at room temperature while shaking to allow sufficient binding of autoantibodies to the PL and proteins immobilized on the PVDF membrane. Unbound serum components were removed by the following wash step with $1 \mathrm{~mL}$ wash buffer containing $10 \mathrm{mM}$ TRIS with $0.1 \%$ Tween 20 for 5 minutes. In a further incubation step of 15 minutes at room temperature, the bound autoantibodies reacted specifically with anti-human IgG or IgM conjugated to horseradish peroxidase (POD). Excessive conjugate was separated from the solid-phase immune complexes by an additional wash step. After addition of $50 \mu \mathrm{L}$ precipitating tetramethylbenzidine as substrate for staining, stripes were dried for at least 30 minutes at room temperature.

Processed strips were analyzed densitometrically employing a scanner with the evaluation software Dr. DotLine Analyzer (GA Generic Assays). Optical density values equaling or above 50 were scored positive. This cutoff was determined by calculating the $99 \%$ percentile of 150 apparently healthy individuals as recommended by the international classification criteria for aPL testing and Clinical and Laboratory Standards Institute (CLSI) guideline C28-A3 [2, 29]. Linearity of dilution with optical density values was demonstrated in the range from 10 to 80 optical density units for most of the aPLpositive samples.

\section{LA testing}

Analysis of LA was performed in accordance with the international recommendations as described recently [30]. LA activity was evaluated in citrated plasma using the ACL TOP coagulation system (Instrumentation Laboratory SpA, Milan, Italy) by the HemosIL ${ }^{\mathrm{Tm}}$ Silica Clotting Time (SCT) and diluted Russell's Viper Venon (dRVVT) screen/confirm assays, together with dRVVT and APTT mixing test, according to manufacturer's protocol and the international guidelines for LA measurement [30].

\section{Statistical analysis and determination of assay performance characteristics}

Fisher's exact test with two-tailed probability was used to test the differences between groups. Inter-rater agreement statistics were applied for comparison of classifications. Rank correlation of variables was performed by Spearman's correlation analysis. Medcalc statistical software (Medcalc, Mariakerke, Belgium) was used for all statistical calculations. $P$ values $<0.05$ were considered significant.

\section{Results \\ Reactivity patterns of monoclonal aPL to PL-binding proteins in the LIA}

To analyze the reactivity to PL-binding proteins employed in the LIA, aß2GPI humoAbs MBB2 and HCAL or monoclonal aPT or polyclonal aAnV were tested: (1) alone, (2) with the addition of the respective antigens, (3) with the addition of ultra-pure BSA as a control protein, and (4) with the addition of normal human serum as a source of the PL-binding proteins. As expected, MBB2 and HCAL humoAbs alone reacted only with immobilized 32 GPI on the LIA membrane (Fig. 1). Likewise, monoclonal aPT and polyclonal aAnV also bound specifically to their corresponding immobilized antigens (Fig. 2).

Co-incubation of the aß2GPI humoAbs with serum revealed additional positive bands, indicating reactivity with immobilized CL, PA, PS, and to a lesser extent with PG and PI. In contrast, such additional bands were not detected for the simultaneous incubation of serum with the polyclonal aPT and aAnV (Fig. 2). The additional bands detected for the aß2GPI humoAb incubation with serum could be reproduced by incubating the immobilized PL on the strips either prior to or simultaneously with purified B2GPI (Fig. 1). B2GPI interacted with the immobilized negatively charged CL, PA, PS, PG and PI in a dose-dependent manner and was subsequently recognized by the aß2GPI humoAbs (data not shown). Thus, the lower reactivity of the HCAL when incubated with serum is probably due to the lower final concentration of $\beta 2 \mathrm{GPI}$ in the diluted serum. 
a

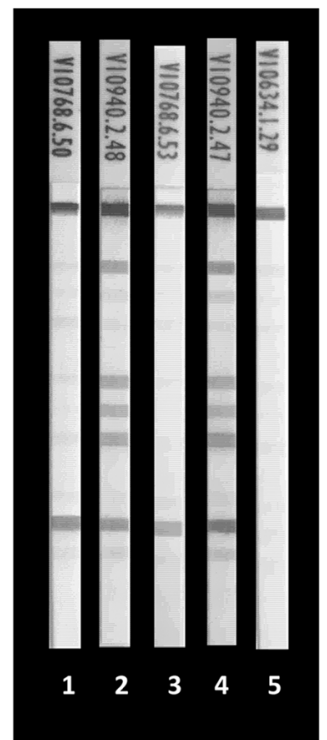

b

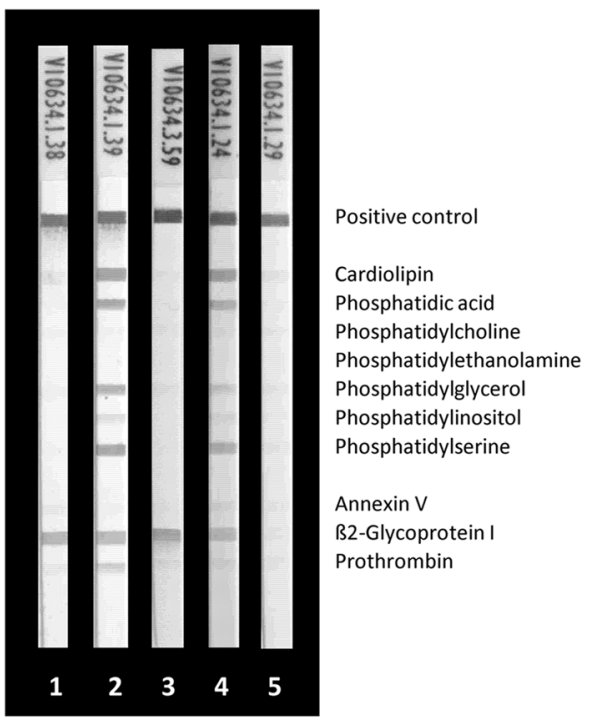

Fig. 1 Reactivity of human monoclonal anti-beta2 glycoprotein I (aß2GPI) antibodies MBB2 (a) and HCAL (b) with phospholipids (PL) and PL-binding proteins by line immunoassay (LIA): MBB2 $(0.1 \mathrm{mg} / \mathrm{L})$ and HCAL $(0.02 \mathrm{mg} / \mathrm{L})$ were run in the LIA alone or together with serum, B2GPI, blood donor serum, and bovine serum albumin (BSA). As the positive reaction control a mixture of human lgG and IgM was immobilized. a 1, $0.1 \mathrm{mg} / \mathrm{L}$ aß32GPI MBB2; $2,0.1 \mathrm{mg} / \mathrm{L}$ aß2GPI MBB2 + $10 \mathrm{mg} / \mathrm{L}$ B2GPI; $3,0.1 \mathrm{mg} / \mathrm{L}$ aß2GPI MBB2 + $10 \mathrm{mg} / \mathrm{L} \mathrm{BSA} ; 4,0.1 \mathrm{mg} / \mathrm{L}$ aß2GPI MBB2 + $30 \mu \mathrm{L}$ serum (1/33); and 5, $30 \mu \mathrm{L}$ serum (1/33). b 1, $0.02 \mathrm{mg} / \mathrm{L}$ aß2GPI HCAL; $2,0.02 \mathrm{mg} / \mathrm{L}$ aß2GPI HCAL + 10 mg/L B2GPI; 3, $0.02 \mathrm{mg} / \mathrm{L}$ aß2GPI HCAL + $10 \mathrm{mg} / \mathrm{L} \mathrm{BSA} ; 4,0.02 \mathrm{mg} / \mathrm{L}$ aß2GPI HCAL + $30 \mu \mathrm{L}$ serum (1/33); and 5, $30 \mu \mathrm{L}$ serum (1/33)
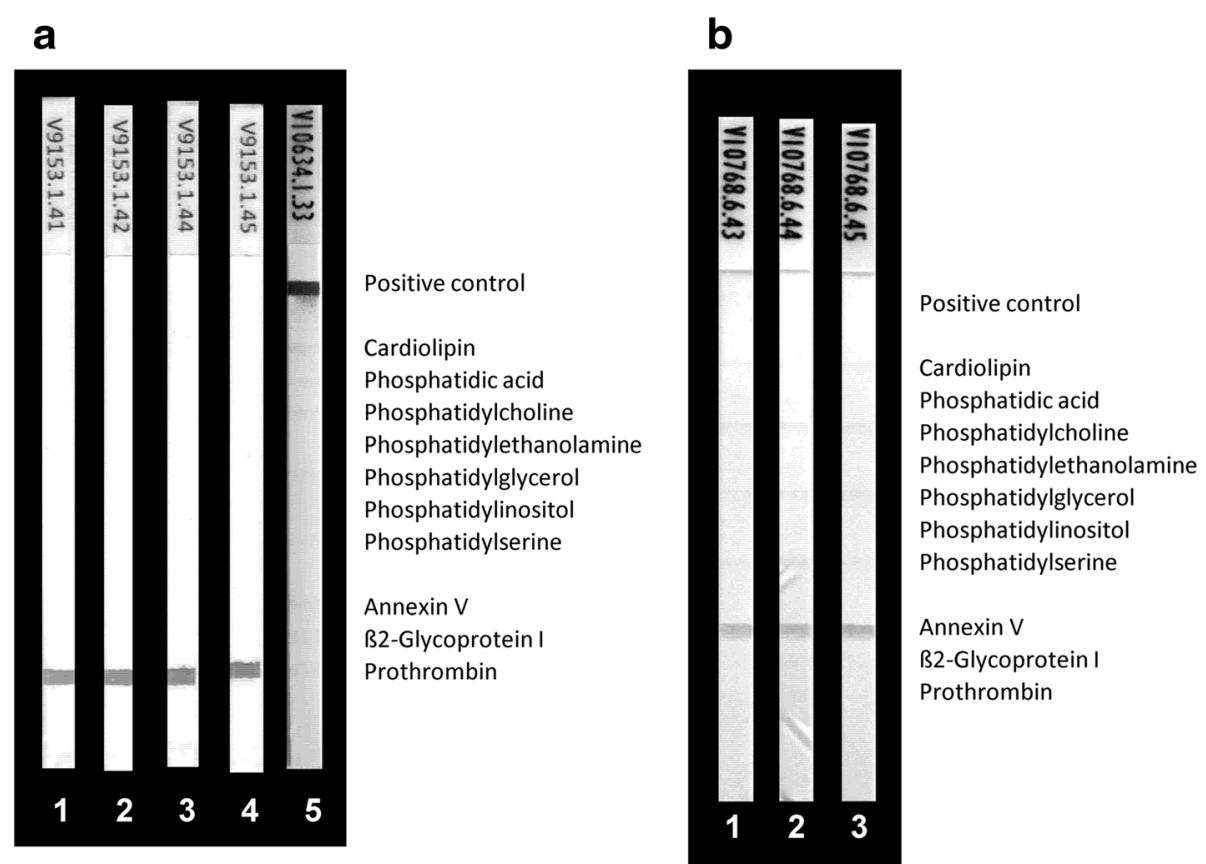

Fig. 2 Reactivity of anti-prothrombin (aPT) mouse monoclonal (a) and anti-annexin V (aAnV) rabbit polyclonal antibodies (b) with phospholipids (PL) and PL-binding proteins by line immunoassay (LIA): aPT and aAnV were run in the LIA alone or together with blood donor serum, bovine serum albumin (BSA) and PT and AnV, respectively. As the positive reaction control a mixture of human lgG and IgM was immobilized. The control band was only revealed when anti-human lgG coupled to horseradish peroxidase was used as secondary antibody conjugate. a 1, 1.0 mg/L aPT;2, $1.0 \mathrm{mg} / \mathrm{L}$ aPT + 10 mg/L PT; 3, 1.0 mg/L aPT + 10 mg/L BSA; 4, 1.0 mg/L aPT + $30 \mu \mathrm{L}$ serum (1/33); and 5, $30 \mu \mathrm{L}$ serum (1/33). b 1,5.0 mg/L aAnV; 2, 5.0 mg/L $\mathrm{aAnV}+10 \mathrm{mg} / \mathrm{L} \mathrm{AnV}$; and 3, $5.0 \mathrm{mg} / \mathrm{L} \mathrm{aAnV}+10 \mathrm{mg} / \mathrm{L} \mathrm{BSA}$ 
In contrast, incubation of PT with the LIA strips followed by $\mathrm{aPT} \mathrm{mAb}$ and of $\mathrm{AnV}$ followed by polyclonal aAnV did not reveal additional bands, indicating no binding of PT and AnV with the immobilized PL (Fig. 2). High $\mathrm{Ca}^{2+}$ ion concentration is known to favor the immunogenic conformational change of $\mathrm{PT}$ in solid phase assays [13]; however, the addition of $\mathrm{Ca}^{2+}$ ions up to a concentration of $20 \mathrm{mM} / \mathrm{L}$ did not affect this reactivity pattern.

The human monoclonal aPL RR7F (IgG) known to be reactive with several $\mathrm{PL}$ in a manner completely independent of PL-binding proteins [25] was employed to investigate the reactivity with $\mathrm{PL}$ on LIA strips (Fig. 3). It showed reactivity with CL, PA, and PS only. Co-incubation of 32 GPI did not interfere with such a reactivity pattern, whereas serum co-incubation revealed less staining of all bands, probably due to unspecific blocking by serum components (Fig. 3). Interestingly, the reactivity of RR7F to PL was completely blocked by $10 \mathrm{mg} / \mathrm{L}$ CL micelles (Fig. 4). In contrast, the aß2GPI reactivity of MBB2 and HCAL was not affected by co-incubation with CL micelles (Fig. 4).

\section{Comparison of aPL testing by LIA and ELISA}

To detect aPL profiles and to analyze possible differences in aPL detection, we tested sera from APS patients and controls by classical ELISA and novel LIA. Comparison of the LIA technique with the aPL assays recommended by the international classification criteria revealed good agreement for IgG/IgM aß2GPI and aCL (Cohen's kappa $=0.78,95 \%$ CI 0.64, 0.88 and $0.72,95 \%$ CI 0.62, 0.82, respectively). On the other hand, comparing the study cohorts, the only significant

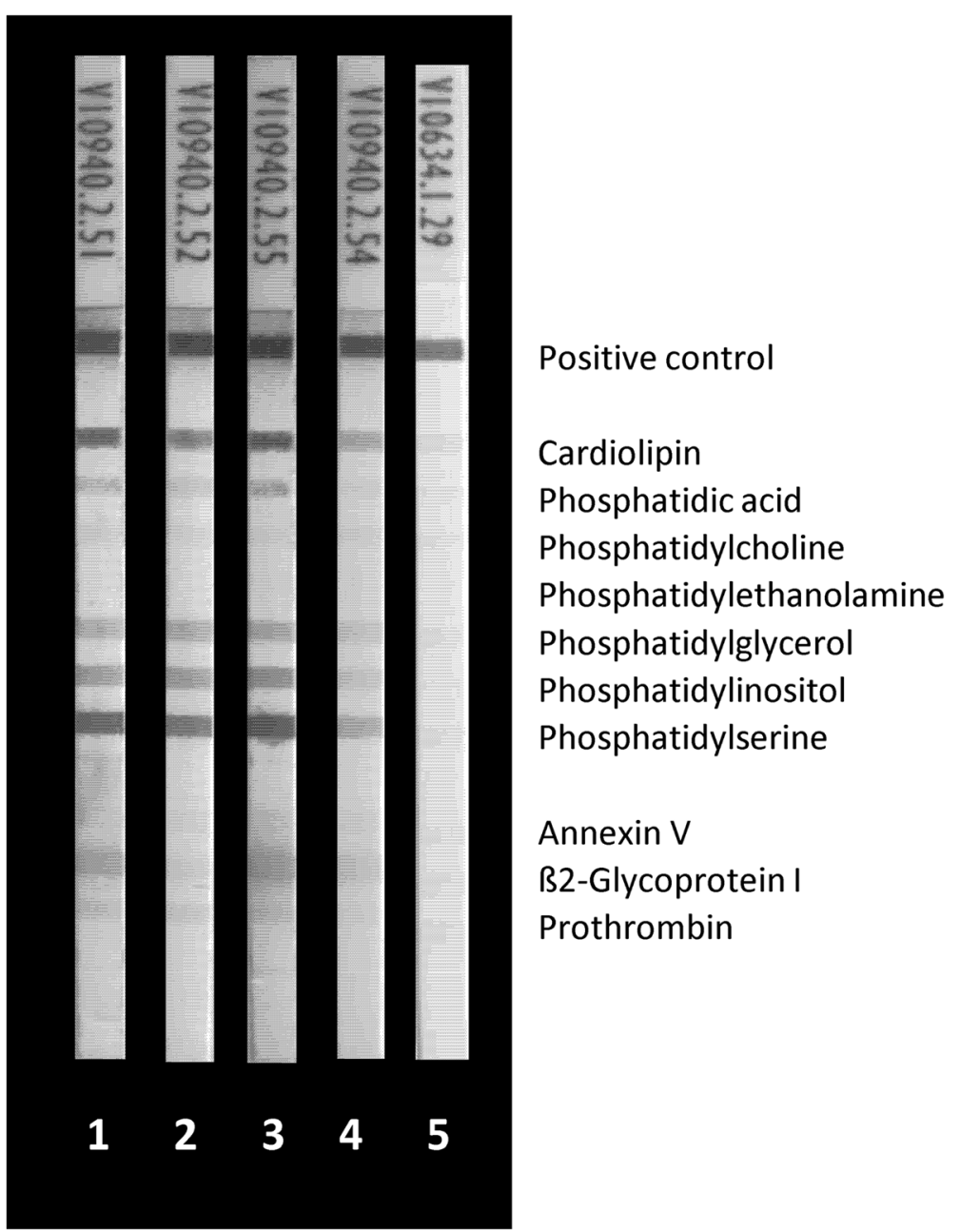

Fig. 3 Reactivity of antiphospholipid (aPL) human monoclonal antibody RR7F with PL and PL-binding proteins by line immunoassay (LIA): RR7F (10.0 mg/L) was run in the LIA alone or together with serum, beta2 glycoprotein I (aß2GPI), blood donor serum, and bovine serum albumin (BSA). As positive reaction control a mixture of human lgG and lgM was immobilized. 1, $10.0 \mathrm{mg} / \mathrm{L}$ RR7F; 2, $10.0 \mathrm{mg} / \mathrm{L}$ RR7F + 10 mg/L B2GPI; 3, 10.0 mg/L $\mathrm{RR7F}+10 \mathrm{mg} / \mathrm{L} \mathrm{BSA} ; 4,10.0 \mathrm{mg} / \mathrm{L} \mathrm{RR7F}+30 \mu \mathrm{L}$ serum (1/33); and 5, $30 \mu \mathrm{L}$ serum (1/33) 


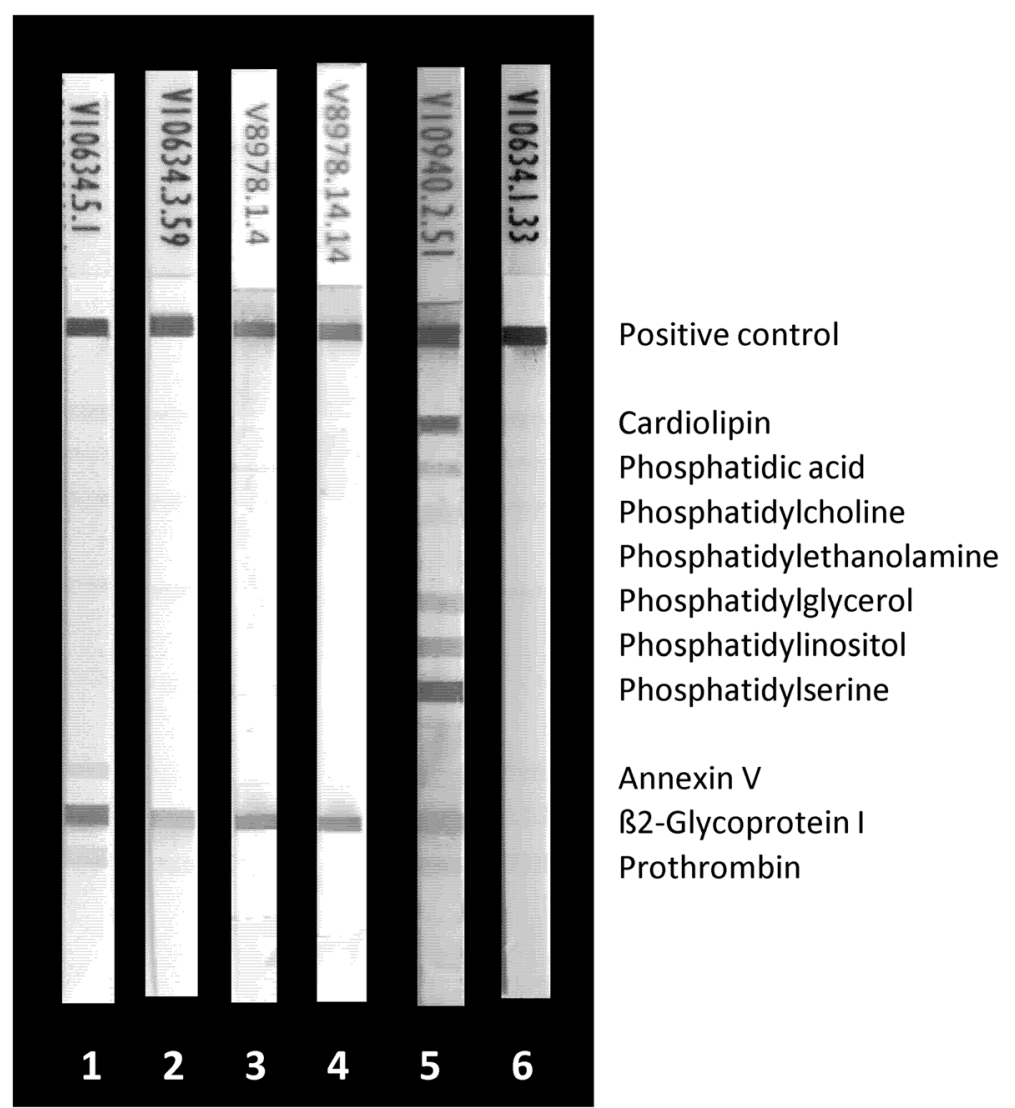

Fig. 4 Inhibition of anti-beta2 glycoprotein I (aß2GPI) human monoclonal antibodies (humoAb) MBB2 and HCAL and antiphospholipid (aPL) humoAb RR7F by cardiolipin (CL) micelles in the line immunoassay (LIA): aß2GPI and aPL humoAb were run in the LIA alone or together with $10 \mathrm{mg} / \mathrm{L} \mathrm{CL}$ micelles. As the positive reaction control a mixture of human $\lg \mathrm{G}$ and $\operatorname{lgM}$ was immobilized. $1,0.1 \mathrm{mg} / \mathrm{L}$ aß2GPI MBB2; $2,0.1 \mathrm{mg} / \mathrm{L}$ aß2GPI MBB2 + CL micelles; 3, $0.02 \mathrm{mg} / \mathrm{L}$ aß2GPI HCAL; 4, $0.02 \mathrm{mg} / \mathrm{L}$ aß32GPI HCAL + CL micelles; $5,10.0 \mathrm{mg} / \mathrm{L}$ aPL RR7F; and 6, $10.0 \mathrm{mg} / \mathrm{L}$ aPL $\mathrm{RR7F}+\mathrm{CL}$ micelles

difference was for IgG aCL detected by LIA versus ELISA in asymptomatic aPL+ carriers (McNemar's test, $29.17 \%$, $95 \%$ CI 5.27, 29.17, $p=0.0156)$. In contrast, IgM aCL did not demonstrate a significant difference by either method in this group $(12.00 \%, 95 \%$ CI $-8.66,19.8$, $p=0.3750$ ). This finding was due to the significantly higher prevalence of IgG/M aCL positive samples detected by ELISA compared with LIA in this group $(17 / 24$ vs. $9 / 24, p=0.0415)$.

Comparing the distinct isotypes of the recommended aPL detected by LIA and ELISA in 161 patients with APS and 156 controls, there was good agreement for $\mathrm{aCL}$ and aß2GPI IgG (Cohen's kappa $=0.75$ and 0.78, respectively) as well as for aCL and aß2GPI IgM (Cohen's kappa $=0.64$ and 0.65 , respectively; Additional file 2: Table S2). On quantitative analysis of aCL IgG and IgM, and aß2GPI IgG and IgM, by LIA and ELISA there was significant correlation, with Spearman correlation coefficients $(\rho)$ ranging from 0.566 to 0.774 , respectively $(p<0.001)$, (Fig. 5).
Comparison of aPL testing in APS patients and controls As expected, patients suffering from APS $(n=61)$ had significantly higher prevalence of IgG/IgM aCL and aß2GPI detected by ELISA compared with those in IDC and HS (Table 2). However, comparing APS with VDRL+ patients, only IgG/IgM aß2GPI were significantly more prevalent in patients with APS (Fig. 6). In contrast, in asymptomatic aPL + carriers the prevalence of all aPL detected by ELISA was not significantly different compared with patients suffering from full-blown APS (Fig. 6).

As a matter of fact, IgG/IgM reactivity against $\mathrm{CL}$ and ß2GPI by LIA was significantly higher in APS samples vs. HS and IDC groups as detected by ELISA. Of note, IgG binding to CL and B2GPI in the LIA was significantly lower in aPL+ carriers and VDRL+ samples than in APS (Fig. 6). Sera that were positive in aCL and/or aß2GPI ELISAs also displayed reactivity with the anionic PL in the LIA strips. Only a minority of samples displayed reactivity against PT, or AnV and PE (mainly of IgM isotype) (Table 2). 
a

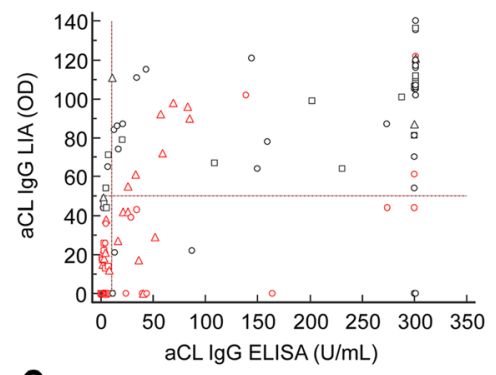

C

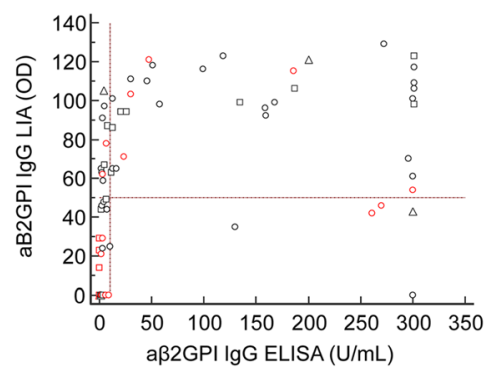

b

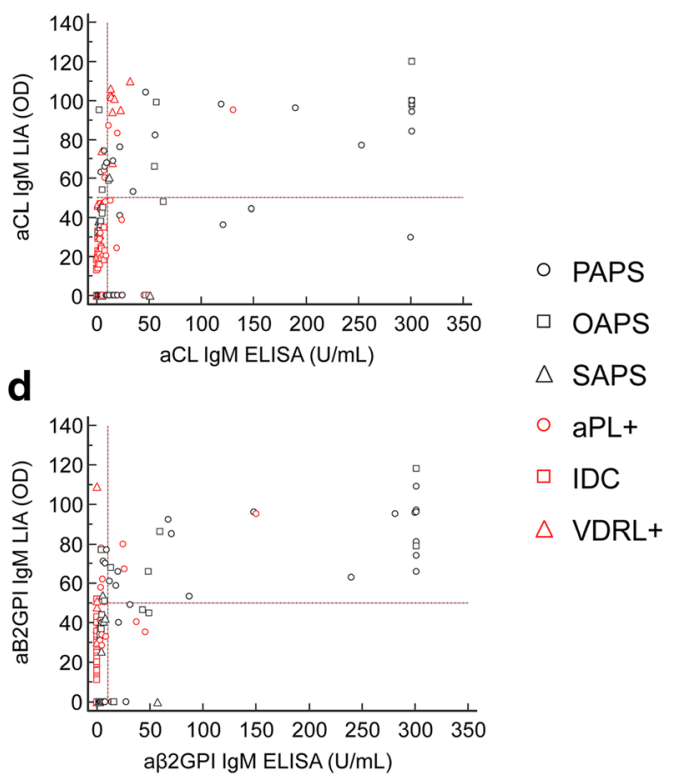

Fig. 5 Spearman's rank correlation analysis of anti-cardiolipin (aCL) IgG (a), aCL IgM (b), anti-beta 2 glycoprotein I (aß2GPI) IgG (c), and aß2GPI $\operatorname{lgM}$ (d) quantitative testing. Antiphospholipid antibodies were determined in 61 patients with antiphospholipid syndrome (APS) and 146 controls by line immunoassay (LIA) and enzyme-linked immunosorbent assay (ELISA). The following correlation coefficients ( $\rho$ ) were obtained for aCL IgG and IgM, and aß2GPI IgG and IgM quantitative testing by LIA and ELISA (aCL IgG: $\rho=0.73795 \% \mathrm{Cl} 0.657,0.801 ; \mathrm{aCL} \operatorname{lgM}: \rho=0.59395 \% \mathrm{Cl} 0.482$, 0.686; aß2GPI IgG: $\rho=0.77495 \% \mathrm{Cl} 0.702,0.830$; aß2GPI IgM: $\rho=0.56695 \% \mathrm{Cl}$ 0.449, 0.663, respectively; $p<0.001$ ). aPL+ asymptomatic patients with autoantibodies to phospholipids, IDC infectious diseases controls, OAPS obstetric antiphospholipid syndrome, PAPS primary antiphospholipid syndrome, SAPS secondary antiphospholipid syndrome, VDRL+ Venereal Disease Research Laboratory test positive, OD optical density

The significant reduced prevalence of aCL and aß2GPI IgG analyzed by LIA in aPL+ carriers compared to APS patients were confirmed by quantitative LIA testing (Fig. 7). The median optical density (OD) level of aCL IgG in aPL+ carriers $(0.1,95 \%$ CI $0.1,43.3)$ was significantly lower than in APS patients (81.0, 95 \% CI 65.8, 101.6, $p=0.0005)$. Likewise, the median OD level of aß2GPI IgG in aPL+ carriers $(0.1,95 \%$ CI $0.1,48.0)$ was significantly reduced in contrast to the one in APS patients (65.0, 95 \% CI 46.8, 93.2, $p=0.0066)$. Such significant differences were not observed by quantitative aCL and aß2GPI IgG ELISA analysis ( $p>0.05$, respectively) (Fig. 7).

In order to investigate the reasons for significant differences on qualitative and quantitative LIA testing of APS patients and controls, we tested nine patients with APS and aPL IgG reactivity to D1 of ß2GPI only and five with aPL reactivity to D4/5 only. Domain reactivity was determined by research assays as described in "Methods". Remarkably, nine of nine patients with APS and sole D1 reactivity scored positive in the LIA, whereas, in contrast none of the five patients with APS and D4/5 reactivity were positive (Table 3$)(p=0.0005)$.

Notably, LA analysis, like ELISA testing, did not reveal significant differences in the prevalence of aPL when comparing patients with APS to asymptomatic aPL+ carriers. Altogether, only aPL IgG analysis by LIA discriminated APS patients from aPL+ carriers.

In this study, evaluating at least one positive assay, the multiplex LIA demonstrated sensitivity of $86.9 \%$ compared to $75.4 \%$ by single ELISAs and $85.2 \%$ by LA analysis. By employing different disease controls, the specificity reached similar values of $74 \%$ for ELISA and $72 \%$ for LIA testing when excluding aAnV IgM, which was positive in all patients with CMV infection $(n=10)$. Sensitivity of $67.2 \%$ by LIA vs. $58.8 \%$ by ELISA at a higher specificity of around $95 \%$ for both techniques has been reported in an earlier study (Table 4).

\section{Comparison of aPL testing in APS patient subgroups}

Comparing patients suffering from PAPS/T and OAPS, there was significantly higher prevalence of aCL determined by ELISA in patients with PAPS/T (27/29 vs. 11/ 22, $p=0.0001$ ). Further, the prevalence of at least one aPL positivity detected by ELISA (aß2GPI IgG/IgM and/ or aCL IgG/IgM positive) was also significantly higher in PAPS/T patients compared to those with OAPS (27/29 vs. $12 / 22, p=0.0021)$. aCL and aPS IgG were also significantly more prevalent in patients with PAPS/T compared to those with OAPS $(p=0.04973$ and $p=0.01154$, 
Table 2 Antiphospholipid antibody (aPL) positive sera tested by enzyme-linked immunosorbent immunoassay (ELISA) and line immunoassay (LIA) in 61 patients with antiphospholipid syndrome (APS) and 146 controls

\begin{tabular}{|c|c|c|c|c|c|c|c|c|c|c|c|c|c|c|c|c|c|c|c|c|c|c|c|c|c|c|c|}
\hline \multicolumn{6}{|l|}{ ELISA } & \multicolumn{21}{|l|}{ LIA } & \multirow[t]{3}{*}{$\overline{L A}$} \\
\hline & \multicolumn{2}{|l|}{$\mathrm{aCl}$} & \multicolumn{2}{|c|}{ aß2GPI } & \multirow{2}{*}{$\begin{array}{l}\text { Any aPL } \\
\text { G/M }\end{array}$} & \multicolumn{2}{|l|}{$\overline{\mathrm{aCl}}$} & \multicolumn{2}{|l|}{ aPA } & \multicolumn{2}{|c|}{$\mathrm{aPC}$} & \multicolumn{2}{|c|}{ aPE } & \multicolumn{2}{|c|}{$\mathrm{aPG}$} & \multicolumn{2}{|l|}{$\mathrm{aPl}$} & \multicolumn{2}{|l|}{ aPS } & \multicolumn{2}{|c|}{$\mathrm{aAnV}$} & \multicolumn{2}{|c|}{$\mathrm{aß2GPI}$} & \multicolumn{2}{|c|}{$\mathrm{aPT}$} & \multirow{2}{*}{$\begin{array}{l}\text { any } \mathrm{aPL} \\
\mathrm{G} / \mathrm{M}\end{array}$} & \\
\hline & $\bar{G}$ & $M$ & $\bar{G}$ & $M$ & & $\bar{G}$ & $M$ & $\bar{G}$ & $M$ & $\bar{G}$ & $\bar{M}$ & $\bar{G}$ & $\bar{M}$ & $\bar{G}$ & $\bar{M}$ & $\bar{G}$ & $M$ & $\bar{G}$ & $M$ & $\bar{G}$ & $M$ & $\bar{G}$ & $M$ & $\bar{G}$ & $\bar{M}$ & & \\
\hline $\begin{array}{l}\text { APS } \\
n=61\end{array}$ & 45 & 31 & 31 & 29 & 46 & 45 & 26 & 31 & 25 & 0 & 0 & 0 & 11 & 18 & 12 & 25 & 16 & 43 & 28 & 3 & 4 & 38 & 29 & 8 & 11 & 53 & 52 \\
\hline $\begin{array}{l}\text { PAPS } \\
n=34\end{array}$ & 31 & 21 & 21 & 20 & 31 & 29 & 18 & 20 & 18 & 0 & 0 & 0 & 7 & 13 & 10 & 17 & 11 & 29 & 20 & 1 & 3 & 25 & 19 & 6 & 6 & 31 & 29 \\
\hline $\begin{array}{l}\mathrm{PAPS} / \mathrm{T} \\
n=29\end{array}$ & 27 & 18 & 17 & 17 & 27 & 25 & 15 & 17 & 15 & 0 & 0 & 0 & 4 & 11 & 9 & 13 & 10 & 25 & 17 & 1 & 2 & 21 & 16 & 5 & 4 & 26 & 24 \\
\hline $\begin{array}{l}\text { PAPS/TO } \\
n=5\end{array}$ & 4 & 3 & 4 & 3 & 4 & 4 & 3 & 3 & 3 & 0 & 0 & 0 & 3 & 2 & 1 & 4 & 1 & 4 & 3 & 0 & 1 & 4 & 3 & 1 & 2 & 5 & 5 \\
\hline $\begin{array}{l}\text { OAPS } \\
n=22\end{array}$ & $11^{\S}$ & 8 & 8 & 8 & $12^{\S}$ & $13^{\S}$ & 7 & 8 & 6 & 0 & 0 & 0 & 4 & 4 & 2 & 7 & 4 & $11^{\S}$ & 7 & 2 & 1 & 10 & 8 & 1 & 4 & 18 & 19 \\
\hline $\begin{array}{l}\text { SAPS } \\
n=5\end{array}$ & 3 & 2 & 2 & 1 & 3 & 3 & 1 & 3 & 1 & 0 & 0 & 0 & 0 & 1 & 0 & 1 & 1 & 3 & 1 & 0 & 0 & 3 & 2 & 1 & 1 & 4 & 4 \\
\hline $\begin{array}{l}\mathrm{aPL}+ \\
n=24\end{array}$ & 13 & 9 & 7 & 6 & 17 & $6^{* *}$ & 6 & $6^{* * *}$ & 6 & 0 & 0 & 0 & $0^{*}$ & 3 & 1 & $4^{*}$ & 3 & $5^{* *}$ & 6 & 0 & 2 & $8^{*}$ & 10 & 1 & 1 & 17 & 20 \\
\hline $\begin{array}{l}\text { IDC } \\
n=50\end{array}$ & $3^{* *}$ & $1^{* *}$ & $0^{* *}$ & $0^{* *}$ & $4^{* *}$ & $0^{* *}$ & $0^{* *}$ & $0^{* *}$ & $0^{* *}$ & 0 & 0 & 0 & $0^{*}$ & $0^{* *}$ & $0^{*}$ & $0^{* *}$ & $1^{*}$ & $0^{* *}$ & $0^{* *}$ & 2 & $10^{*}$ & $0^{* *}$ & $1^{* *}$ & $1^{*}$ & 4 & $16^{* *}$ & nd \\
\hline $\begin{array}{l}\text { VDRL }+ \\
n=23\end{array}$ & 13 & 8 & $3^{*}$ & $1^{*}$ & 15 & $7^{*}$ & 9 & $0^{* *}$ & $1^{*}$ & 0 & 0 & 0 & 1 & $0^{*}$ & $1^{*}$ & $0^{*}$ & $1^{*}$ & $0^{* *}$ & $1^{*}$ & 1 & 2 & $0^{* *}$ & $2^{*}$ & 0 & 5 & $12^{*}$ & nd \\
\hline $\begin{array}{l}\mathrm{HS} \\
n=49\end{array}$ & $0^{* *}$ & $2^{* *}$ & $0^{* *}$ & $0^{* *}$ & $2^{* *}$ & $1^{* *}$ & $1^{* *}$ & $1^{* *}$ & $0^{* *}$ & 0 & 0 & 0 & 4 & $0^{* *}$ & $0^{*}$ & $1^{* *}$ & $0^{* *}$ & $1^{* *}$ & $0^{* *}$ & 0 & 0 & $0^{* *}$ & $0^{* *}$ & $0^{*}$ & $0^{*}$ & $6^{* *}$ & nd \\
\hline
\end{tabular}

${ }^{*} P<0.05$ and ${ }^{* *} p<0.0001$ for comparison of prevalence of aPL in patients with APS $(n=61)$ and the respective control cohort; ${ }^{* * *}$ trend towards difference in prevalence of aPL in patients with APS $(n=61)$ and the respective control cohort $(p=0.05) .{ }^{5} P<0.05$ for comparison of prevalence of aPL in PAPS/T patients $(n=29)$ with SAPS or OAPS patients. aAnV antiannexin V, aß2GPI antibeta2-glycoprotein I, $a C L$ anticardiolipin, $a P A$ antiphosphatidic acid, $a P C$ antiphosphatidylcholine, $a P E$ antiphosphatidylethanolamine, $a P G$ antiphosphatidylglycerol, $a P I$ antiphosphatidylinositol, $a P L+$ asymptomatic patients with autoantibodies to phospholipids, aPS antiphosphatidylserine, aPT antiprothrombin, HS healthy subjects, IDC infectious diseases controls, LA lupus anticoagulant, nd not determined, OAPS obstetric primary antiphospholipid syndrome, PAPS primary antiphospholipid syndrome, PAPST primary antiphospholipid syndrome with thrombotic events, PAPS/TO primary antiphospholipid syndrome with thrombotic and obstetric manifestations, SAPS secondary antiphospholipid syndrome, VDRL+ Venereal Disease Research Laboratory test-positive

respectively) in the LIA test. Of note, there was no significant difference in the prevalence of aPL when comparing patients with PAPS/T and OAPS in analysis of LA.

\section{Discussion}

The persistent presence of aPL is the serological hallmark of APS and represents one of its mandatory classification criteria [2]. It is a well-accepted consensus that aPL interact with PL-binding proteins. While most of the reactivity was against $\beta 2 \mathrm{GPI}$, additional PL-binding proteins were shown to be recognized by aPL $[11-13,16]$. The different aPL subpopulations cannot be detected by a single diagnostic assay and this supports the recommendation for performing $\mathrm{aCL}$, aß2GPI, and LA assays in order to identify all the potential aPL.

Between $1 \%$ and $5 \%$ of healthy individuals have circulating aPL that are detectable with the currently recommended aPL assays [4]. This raises the issue of identifying the truly diagnostic aPL and/or those aPL that are really predictive for the clinical manifestations of the syndrome.
The LIA membrane strips provide a unique matrix that allows PL to mimic their natural conformation in tissues as reported for other amphiphatic non-protein antigenic molecules [28, 31-33]. Hence, immobilized PL offer a suitable binding substrate for the main PLbinding proteins. Accordingly, this study investigated the performance of a novel LIA hydrophobic solid phase for the simultaneous detection of multiple aPL in a welldefined cohort of patients with APS and controls including aPL+ asymptomatic carriers.

Of note, the novel LIA solid phase has already proven its usefulness for the specific analysis of auto-antibodies to lipopolysaccharides and glycolipids exhibiting PL-like physicochemical characteristics $[28,33]$. In contrast to the planar ELISA solid phase, the porous hydrophobic LIA membrane is assumed to incorporate the hydrophobic PL tail. This shields the by far larger tail of the amphiphatic PL molecule from the reaction environment and, thus, prevents unspecific interactions [11]. Of note, the humoAb RR-7 F interacting with anionic PL only in ELISA also bound readily immobilized anionic PL in the investigated LIA [25]. This reactivity was 


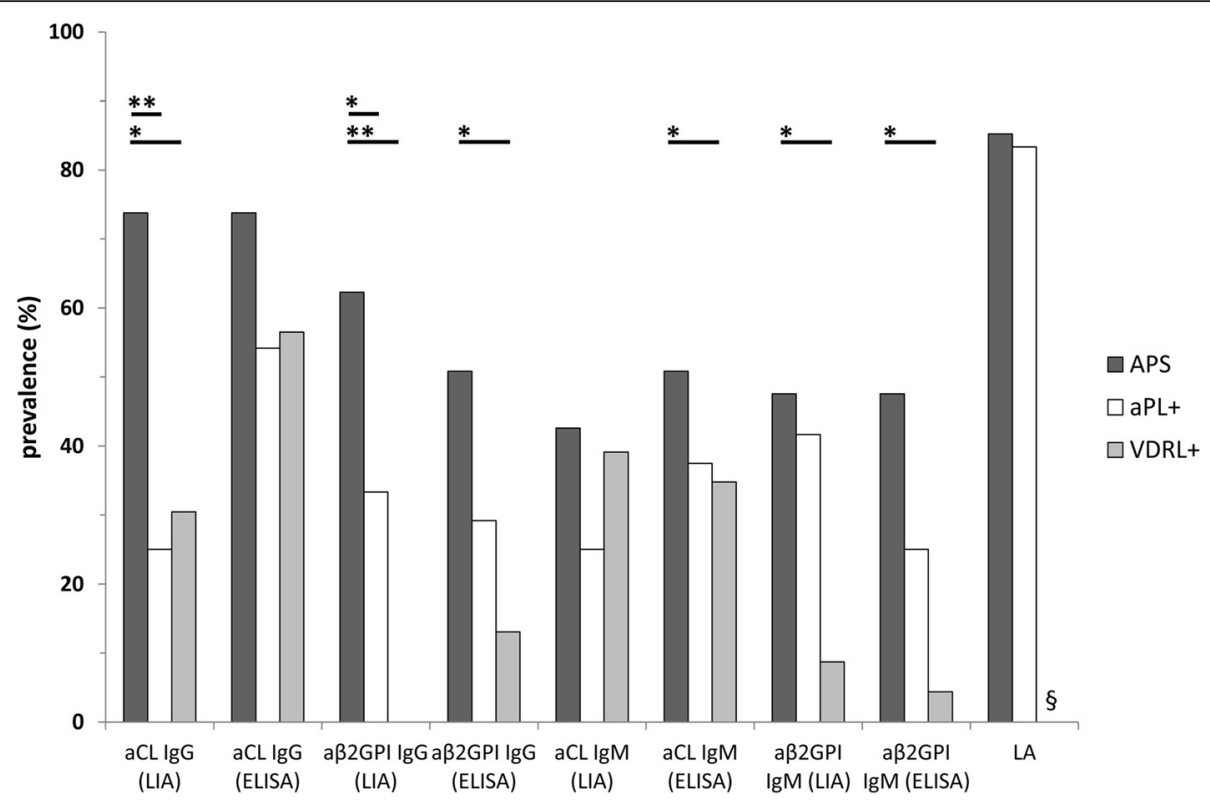

Fig. 6 Prevalence of consensus criteria antiphospholipid antibodies (aPL) tested by line immunoassay (LIA), enzyme-linked immunosorbent assay (ELISA), and lupus anticoagulant (LA) analysis in 61 patients with antiphospholipid syndrome (APS), 24 aPL-positive (aPL+) individuals, and 23 Veneral Disease Laboratory test-positive (VDRL+) patients. aß2GPI antibeta2-glycoprotein I, aCL anticardiolipin, aPA antiphosphatidic acid, aPE antiphosphatidylethanolamine, $a P G$ antiphosphatidylglycerol, $a P$ I antiphosphatidylinositol, $a P L+$ asymptomatic carriers with autoantibodies to phospholipids, aPS antiphosphatidylserine. ${ }^{*} P<0.05 ;{ }^{* *} p<0.0001$; ${ }^{\S}$ not done

completely inhibited by CL micelles that expose only hydrophilic CL-heads on their surface in aqueous solutions. Consequently, this confirms the interaction of RR$7 \mathrm{~F}$ with the hydrophilic PL-heads on the PVDF membrane. The aß2GPI humoAbs MBB2 and HCAL were able to recognize their target molecule coated on the membrane as well as to react with anionic PL through the bound cationic $\beta 2$ GPI.

Interestingly, the addition of serum or purified $\beta 2 \mathrm{GPI}$ to MBB2 revealed different binding characteristics to the immobilized anionic PL in the novel reaction environment. CL, also referred to as diphosphatidylglycerol, binds $\beta 2$ GPI far better than its monomeric variant PG. Otherwise, PS bearing only one phosphatic group has a better binding than PI or PG. This supports the assumption that the number, orientation, and accessibility of anionic phosphatic groups in the hydrophilic PL heads determine the binding of $\beta 2 \mathrm{GPI}$ and consequently of the $\beta 2$ GPI-dependent aPL. As MBB2 has been demonstrated to specifically react with D1 of B2GPI and its conformational epitope [24], its binding to the LIA strips indicates that the immobilized $\beta 2$ GPI readily exposes D1. This demonstrates the accessibility of this important pathogenic epitope-bearing domain in the LIA reaction environment. As a consequence, these variables may affect the ultimate serum autoantibody binding.

Indeed, favorable assay performance particularly for the specificity of this novel LIA technique for the analysis of aPL has been reported recently and was confirmed in this study $[17,21]$. In fact, the prevalence of $\mathrm{aCL}$ and $\mathrm{aß2GPI} \operatorname{IgG}$ was significantly reduced in aPL+ carriers and in VDRL+ individuals compared to patients with APS when analyzed by LIA but not by ELISA. Of note, the significantly qualitative differences of aCL IgG and aß2GPI IgG testing by LIA in APS patients and aPL+ carriers were confirmed by quantitative analyses of the respective median OD levels.

We could not determine the binding of either serum or purified PT with immobilized anionic PL, particularly with PS, in the multiplex LIA environment as shown for $\beta 2$ GPI. Even in the presence of $\mathrm{Ca}^{+2}$ ions, which are required for the aPT/PS ELISA reaction environment, no binding was detected. However, it cannot be excluded that the PT in the LIA reaction environment is not able to change its conformation in the presence of $\mathrm{Ca}^{2+}$ ions. This point could not be addressed by our experimental setting. Addition of further PT in the presence of the right high $\mathrm{Ca}++$ concentration did not change the binding behavior. Of note, there was a significantly different prevalence of aPT and aPS IgG/IgM $(p<0.0001$ and $p=0.0017$, respectively $)$ in APS patients by LIA. Altogether, this indicates that aPS reactivity in LIA is mainly based on the reactivity to $\beta 2$ GPI bound to PS and does not involve PT present in the serum sample. Theoretically in fact, 


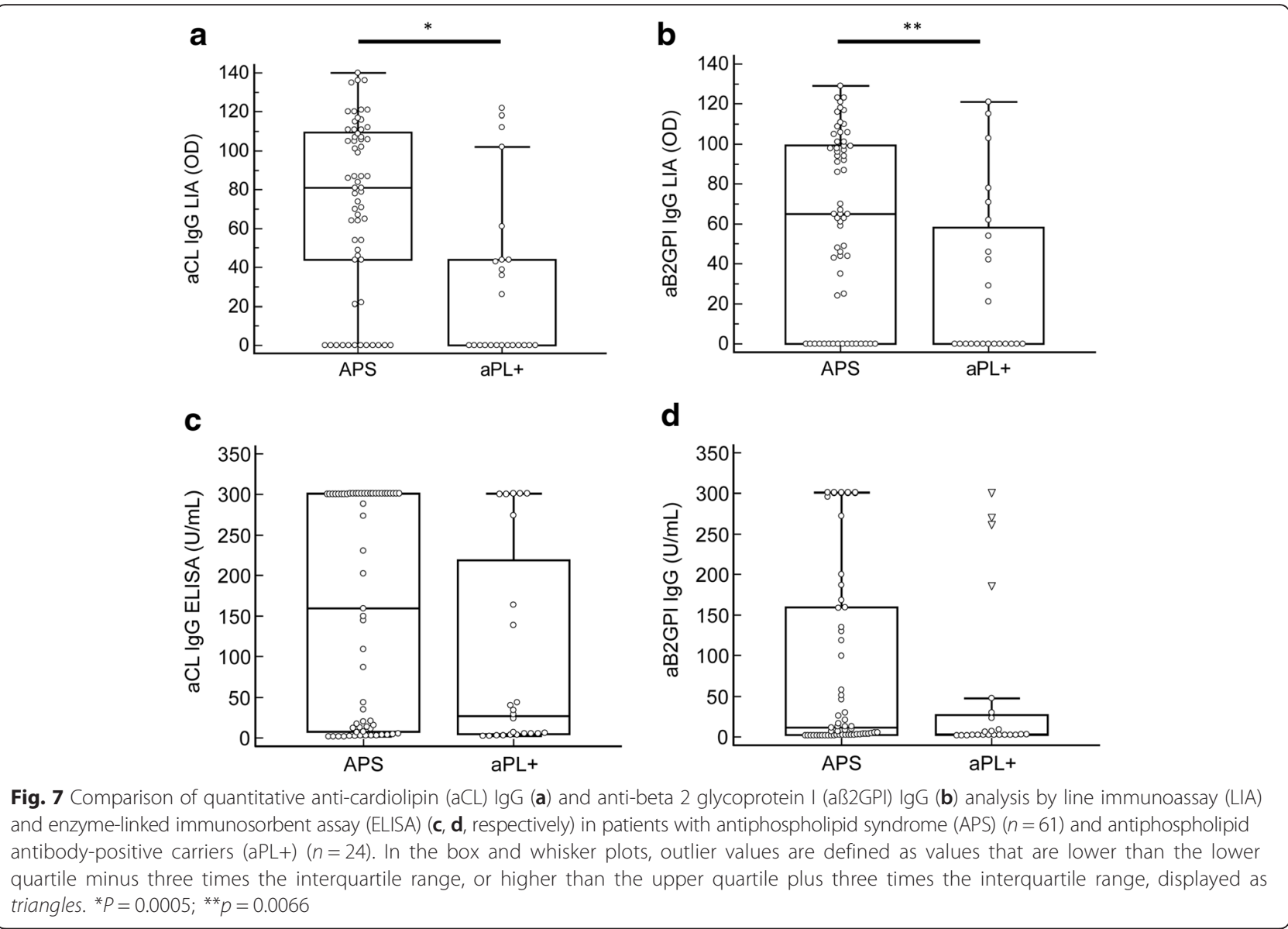

Table 3 Line immunoassay (LIA) reactivity of antibeta2-glycoprotein I (aß2GPI) domain 1 (D1) negative-D4/5 positive and D1 positive-D4/5 negative sera from patients (Pts) with antiphospholipid syndrome (APS)

\begin{tabular}{|c|c|c|c|c|c|c|c|c|c|c|c|}
\hline \multirow[b]{2}{*}{ aß2GPI reactivity profile } & \multirow[b]{2}{*}{ Pt \# } & \multicolumn{9}{|c|}{ aPL IgG reactivity by LIA (OD) } & \multirow[b]{2}{*}{ aPT } \\
\hline & & $\overline{\mathrm{aCl}}$ & aPA & $\mathrm{aPC}$ & $\mathrm{aPE}$ & $\mathrm{aPG}$ & $\mathrm{aPI}$ & aPS & aAnV & $\overline{a ß 2 G P I}$ & \\
\hline \multirow[t]{5}{*}{ aD1 negative-aD4/5 positive } & 1 & 0 & 0 & 0 & 0 & 0 & 0 & 0 & 0 & 20 & 0 \\
\hline & 2 & 0 & 0 & 0 & 0 & 0 & 0 & 0 & 0 & 30 & 0 \\
\hline & 3 & 0 & 17 & 0 & 0 & 0 & 0 & 0 & 0 & 0 & 0 \\
\hline & 4 & 0 & 0 & 0 & 0 & 0 & 0 & 0 & 0 & 27 & 0 \\
\hline & 5 & 0 & 0 & 0 & 0 & 0 & 0 & 0 & 0 & 34 & 0 \\
\hline \multirow[t]{9}{*}{ aD1 positive-aD4/5 negative* } & 6 & 108 & 80 & 0 & 0 & 0 & 0 & 109 & 0 & 97 & 0 \\
\hline & 7 & 121 & 107 & 0 & 35 & 84 & 94 & 116 & 44 & 121 & 83 \\
\hline & 8 & 87 & 45 & 0 & 0 & 41 & 58 & 92 & 0 & 65 & 0 \\
\hline & 9 & 111 & 68 & 0 & 0 & 85 & 91 & 101 & 0 & 98 & 37 \\
\hline & 10 & 136 & 107 & 0 & 0 & 109 & 117 & 131 & 33 & 123 & 80 \\
\hline & 11 & 99 & 66 & 0 & 0 & 49 & 69 & 93 & 0 & 86 & 0 \\
\hline & 12 & 136 & 104 & 0 & 0 & 99 & 94 & 121 & 56 & 123 & 82 \\
\hline & 13 & 116 & 83 & 0 & 0 & 100 & 106 & 126 & 0 & 118 & 33 \\
\hline & 14 & 135 & 121 & 0 & 0 & 91 & 106 & 121 & 0 & 116 & 50 \\
\hline
\end{tabular}

Results of antiphospholipid (aPL) IgG are expressed as optical density (OD) values whereas OD values equaling or above 50 were scored positive (positive values in italics). $a A n V$ antiannexin $\mathrm{V}, a C L$ anticardiolipin, $a P A$, antiphosphatidic acid; $a P C$, antiphosphatidylcholine; $a P E$ antiphosphatidylethanolamine, $a P G$ antiphosphatidylglycerol, aPI antiphosphatidylinositol, aPS antiphosphatidylserine, aPT antiprothrombin. ${ }^{*} P=0.0005$ vs aD1 negative-aD4/5 positive 
Table 4 Comparison of the performance characteristics of enzyme-linked immunosorbent assay (ELISA), line immunoassay (LIA) and lupus anticoagulant $(L A)$ testing of this study investigating 61 patients with APS and 156 controls with previously published data comprising 85 patients with APS and 144 controls [17]

\begin{tabular}{llccccccccc}
\hline Cohorts & & Sensitivity & $95 \% \mathrm{Cl}$ & Specificity & $95 \% \mathrm{Cl}$ & $+\mathrm{LR}$ & $95 \% \mathrm{Cl}$ & $-\mathrm{LR}$ & $95 \% \mathrm{Cl}$ \\
\hline $\begin{array}{l}\text { 61 Patients with APS, } 157 \text { controls including 25 } \\
\text { asymptomatic carriers }\end{array}$ & ELISA & 75.4 & $62.7-85.5$ & 74.0 & $66.1-80.9$ & 2.9 & $2.1-4.0$ & 0.3 & $0.2-0.5$ \\
& LIA* & 86.9 & $75.8-94.2$ & 78.8 & $71.2-85.1$ & 4.1 & $3.0-5.7$ & 0.2 & $0.1-0.3$ \\
85 Patients with APS, 144 controls [17] & ELISA & 58.8 & $47.6-69.4$ & 95.8 & $91.1-98.5$ & 14.1 & $6.3-31.5$ & 0.4 & $0.3-0.6$ \\
& LIA & 67.1 & $56.0-76.9$ & 96.5 & $92.1-98.9$ & 19.3 & $8.1-46.3$ & 0.3 & $0.2-0.5$ \\
\hline
\end{tabular}

*Anti-annexin $\mathrm{V}$ antibody data for patients with cytomegalovirus infection $(n=10)$ were excluded. $C l$ confidence interval, $L R$ likelihood ratio

serum PT could bind PS on the PVDF membrane. Accordingly, in our study there was no significant correlation between thrombotic events and either aPT or aPS detected by LIA, which was reported for aPS/ PT elsewhere [12]. The latter findings is in line with the hypothesis that aPS/PT abs recognize a peculiar epitope(s) exposed on PT only when complexed with PS-coated polystyrene plates.

A further novelty of this aPL assay is the possibility of detecting antibodies against D1 because of the way the molecule is oriented on the matrix [34, 35]. After binding of $\beta 2$ GPI to negatively charged surfaces like immobilized anionic PL by D5 (containing the PLbinding site), D1 forms the top of the induced fishhook-like $\beta 2$ GPI structure that is predisposed to interact with aPL [35]. Assuming a high density of the hydrophilic PL heads on the LIA membrane, 32GPI D4 and D5 could be indeed engaged in the binding of immobilized PL and no longer available for aPL interaction. Indeed, none out of five patients with APS with D4/D5 reactivity only, had a positive aPL IgG by LIA, whereas all nine patients with D1 reactivity only did have positive aPL by LIA. aPL directed against D1 are significantly more present in sera in APS than in pathological controls such as infectious patients or aPL+ asymptomatic carriers. On the other hand, aPL reacting with $\beta 2 \mathrm{GPI}$ D4 and D5 display opposite behavior [36, 37]. Indeed, there is a significant difference in the analysis of aPL binding to anionic PL/B2GPI complexes in LIA compared with ELISA in VDRL+ patients and in particular in asymptomatic aPL+ carriers. Thus, the significantly lower prevalence of aPL detected by LIA in aPL+ carriers and in VDRL+ patients indicates more specific detection of diagnostic aPL by LIA. Remarkably, on aPL analysis by LA testing and ELISA there were no such significant differences, which suggests the detection of aPL to epitopes other than those present on D1. As the aPL reactivity to D4-5 has been reported not to be associated with thromboembolism, our data further support the suggestion that LIA may detect aPL that are more predictive of clinical events in APS [36-38].

\section{Conclusions}

This is the first study reporting on a diagnostic assay for discrimination of patients with APS from asymptomatic aPL carriers and patients with infectious diseases. The varying aPL reactivity detected in LIA could be explained by conformational differences in the fishhooklike structure of $\beta 2 \mathrm{GPI}$ interacting with PL heads homogenously oriented on the membrane.

\section{Additional files}

Additional file 1: Table S1. Clinical and laboratory features of patients with antibeta2-glycoprotein I (aß2GPI) domain 1 (D1) antibody negativeD4/5 positive and D1 positive-D4/5 negative antiphospholipid syndrome (APS). (DOCX $23 \mathrm{~kb}$ )

Additional file 2: Table S2. Comparison of antiphospholipid antibody (aPL) testing by line immunoassay (LIA) and enzyme-linked immunosorbent assay (ELISA) in 61 patients with APS and 156 controls. (DOCX 16 kb)

\section{Abbreviations}

aAnV: antiannexin $V$ antibody; aCL: anti-cardiolipin antibody; AnV: annexin $V_{\text {; }}$ aPL: antiphospholipid antibody(ies); aPL+: antiphospholipid antibody positive; APS: antiphospholipid syndrome; aPT: antiprothormbin antibody; BSA: bovine serum albumin; CL: cardiolipin; D1-D5: domains 1-5; ELISA: enzyme-linked immunosorbent assay; HS: healthy subjects; humoAb(s): human monoclonal antibody(ies); IDC: infectious diseases controls; LA: lupus anticoagulant; LIA: line immunoassay; mAb: monoclonal antibodies; OAPS: obstetric primary antiphospholipid syndrome; OD: optical density; PAPS: primary antiphospholipid syndrome; PBS: phosphate-buffered saline; PC: phosphatidylcholine; PE: phosphatidylethanolamine; PG: phosphatidylglycerol; PI: phosphatidylinositol; PL: phospholipid; PS: phosphatidylserine; PT: prothrombin; PVDF: polyvinylidene difluoride; SAPS: secondary antiphospholipid syndrome; VDRL+: Venereal Disease Research Laboratory test positive; $\beta 2 \mathrm{GPI}$ : beta2-glycoprotein I.

\section{Competing interests}

Dirk Roggenbuck has a management role and is a shareholder of GA Generic Assays $\mathrm{GmbH}$ and Medipan $\mathrm{GmbH}$. Both companies are diagnostic manufacturers. He has no non-financial conflict of interest. Michael Mahler is employed at Inova Diagnostics selling autoantibody assays. Pier Luigi Meroni received consultant fees from Inova Diagnostics. All the other authors declare that they have no financial competing interests or non-financial conflicts of interest.

Claudia Grossi is supported by a grant from the IRCCS Istituto Auxologico Italiano. This research received no specific grant from any funding agency in the public, commercial, or not-for-profit sectors.

\section{Authors' contributions}

DR conceived of the study, wrote the manuscript and revision, and performed antiphospholipid antibody analysis and statistical analysis. MOB wrote the manuscript, did the statistical evaluation of the data, and performed 
antiphospholipid antibody analysis. VS wrote the manuscript, did the statistica evaluation of the data, and performed antiphospholipid antibody analysis. TB did the statistical evaluation of the data, performed antiphospholipid antibody analysis, and helped with the revision. PS conceived of the study, did the statistical evaluation of the data, performed antiphospholipid antibody analysis, and helped with the revision. $\mathrm{KH}$ generated and purified human monoclonal antiphospholipid antibodies, did the reactivity studies, and helped with the revision. CG did the statistical evaluation of the data, performed antiphospholipid antibody analysis, and helped with the revision. CB did the statistical evaluation of the data and performed antiphospholipid antibody analysis, and helped with the revision. PM developed the monoclonal antibody to D1 of b2GPI (MBB2), carried out reactivity MBB2 experiments, and helped with the revision. PL generated and purified human monoclonal antiphospholipid antibodies, did the reactivity studies, and helped with the revision. FB performed the antiphospholipid antibody analysis and inhibition experiments, did statistical analysis of the data, and helped with the revision. MM performed the antiphospholipid antibody analysis for domain reactivity and helped with the revision. PLM conceived of the study, wrote the manuscript and revision, and recruited patients and controls. All authors read and approved the manuscript.

\section{Author details}

${ }^{1}$ Institute of Biotechnology, Faculty 2, Brandenburg University of Technology Cottbus-Senftenberg, Großenhainer Str. 57, 01968 Senftenberg, Germany. ${ }^{2}$ Research and Development Department, Medipan GmbH, Dahlewitz/Berlin, Germany. ${ }^{3}$ Department of Clinical Science and Community Health, University of Milan, Milan, Italy. ${ }^{4}$ Istituto Auxologico Italiano, Laboratory of Immunorheumatology, Cusano Milanino, Italy. ${ }^{5}$ Research and Development Department, GA Generic Assays GmbH, Dahlewitz/Berlin, Germany. ${ }^{6}$ Chair Immuntechnology, Department of Biochemistry and Biology, University of Potsdam, Potsdam, Germany. ${ }^{7}$ Department of Life Sciences, University of Trieste, Trieste, Italy. ${ }^{8}$ Labor Nordwest, Schüttorf, Germany. ${ }^{9}$ Max Planck Institute for Infection Biology, Berlin, Germany. ${ }^{10}$ Inova Diagnostics, San Diego, CA, USA.

\section{Received: 23 December 2015 Accepted: 11 May 2016 Published online: 21 May 2016}

\section{References}

1. Ruiz-Irastorza G, Crowther M, Branch W, Khamashta MA. Antiphospholipid syndrome. Lancet. 2010;376(9751):1498-509.

2. Miyakis S, Lockshin MD, Atsumi T, Branch DW, Brey RL, Cervera R, et al. International consensus statement on an update of the classification criteria for definite antiphospholipid syndrome (APS). J Thromb Haemost. 2006;4(2):295-306.

3. Meroni PL, Chighizola CB, Rovelli F, Gerosa M. Antiphospholipid syndrome in 2014: more clinical manifestations, novel pathogenic players and emerging biomarkers. Arthritis Res Ther. 2014;16(2):209.

4. Biggioggero M, Meroni PL. The geoepidemiology of the antiphospholipid antibody syndrome. Autoimmun Rev. 2010;9(5):A299-304.

5. Pengo V. APS-controversies in diagnosis and management, critical overview of current guidelines. Thromb Res. 2011;127 Suppl 3:S51-2.

6. Pierangeli SS, Favaloro EJ, Lakos G, Meroni PL, Tincani A, Wong RC, et al. Standards and reference materials for the anticardiolipin and antibeta(2)glycoprotein I assays: A report of recommendations from the APL Task Force at the 13th International Congress on Antiphospholipid Antibodies. Clin Chim Acta. 2012;413(1-2):358-60.

7. Devreese K, Hoylaerts MF. Challenges in the diagnosis of the antiphospholipid syndrome. Clin Chem. 2010;56(6):930-40.

8. Meroni PL, Biggioggero M, Pierangeli SS, Sheldon J, Zegers I, Borghi MO. Standardization of autoantibody testing: a paradigm for serology in rheumatic diseases. Nat Rev Rheumatol. 2014;10(1):35-43.

9. Chighizola CB, Raschi E, Borghi MO, Meroni PL. Update on the pathogenesis and treatment of the antiphospholipid syndrome. Curr Opin Rheumatol. 2015;27(5):476-82.

10. Pengo V, Biasiolo A, Pegoraro C, Cucchini U, Noventa F, lliceto S. Antibody profiles for the diagnosis of antiphospholipid syndrome. Thromb Haemost. 2005;93(6):1147-52.

11. Roggenbuck D, Egerer $K$, von Landenberg $P$, Hiemann R, Feist $E$, Burmester G-R, et al. Antiphospholipid antibody profiling - time for a new technical approach. Autoimmun Rev. 2012;11(11):821-6.
12. Hoxha A, Ruffatti A, Mattia E, Meneghel L, Tonello M, Salvan E, et al. Relationship between antiphosphatidylserine/prothrombin and conventional antiphospholipid antibodies in primary antiphospholipid syndrome. Clin Chem Lab Med. 2015;446:201-5.

13. Bertolaccini ML, Amengual $O$, Andreoli L, Atsumi T, Chighizola CB, Forastiero R, et al. 14th International Congress on Antiphospholipid Antibodies Task Force. Report on antiphospholipid syndrome laboratory diagnostics and trends. Autoimmun Rev. 2014;13(9):917-30.

14. Pengo V, Banzato A, Denas G, Jose SP, Bison E, Hoxha A, et al. Correct laboratory approach to APS diagnosis and monitoring. Autoimmun Rev. 2013;12(8):832-4.

15. Del Ross T, Ruffatti A, Cuffaro S, Tonello M, Calligaro A, Favaro M, et al. The clinical relevance of the IgM isotype of antiphospholipid antibodies in the vascular antiphospholipid syndrome. Thromb Res. 2015;136:883-6.

16. Meroni PL, Borghi MO, Raschi E, Tedesco F. Pathogenesis of antiphospholipid syndrome: understanding the antibodies. Nat Rev Rheumatol. 2011;7(6):330-9.

17. Egerer K, Roggenbuck D, Buettner T, Lehmann B, Kohn A, von Landenberg P, et al. Single-step autoantibody profiling in antiphospholipid syndrome using a multi-line dot assay. Arthritis Res Ther. 2011;13(4):R118.

18. Roggenbuck D, Egerer K, Feist E, Burmester GR, Dorner T. Antiphospholipid antibody profiling - association with the clinical phenotype in APS? Arthritis Rheum. 2012;64(8):2807-8.

19. Mattia E, Ruffatti A, Meneghel L, Tonello M, Faggian D, Hoxha A, et al. A contribution to detection of anticardiolipin and anti- $\beta 2$ glycoprotein I antibodies: Comparison between a home-made ELISA and a fluorescence enzyme immunoassay. Clin Chim Acta. 2015;446:93-6.

20. Zhang S, Wu Z, Li P, Bai Y, Zhang F, Li Y. Evaluation of the clinical performance of a novel chemiluminescent immunoassay for detection of anticardiolipin and anti-beta2-glycoprotein 1 antibodies in the diagnosis of antiphospholipid syndrome. Medicine (Baltimore). 2015;94(46), e2059.

21. Roggenbuck D, Somma V, Schierack P, Borghi MO, Meroni PL. Autoantibody profiling in APS. Lupus. 2014;23:1262-4.

22. Andreoli L, Chighizola CB, Nalli C, Gerosa M, Borghi MO, Pregnolato F, et al. Antiphospholipid antibody profiling: the detection of IgG antibodies against beta2glycoprotein i domain 1 and 4/5 offers better clinical characterization: the ratio between anti-D1 and anti-D4/5 as a new useful biomarker for APS. Arthritis Rheumatol. 2015;67(8):2196-204.

23. Ichikawa K, Tsutsumi A, Atsumi T, Matsuura E, Kobayashi S, Hughes GR, et al. A chimeric antibody with the human gamma1 constant region as a putative standard for assays to detect lgG beta2-glycoprotein I-dependent anticardiolipin and anti-beta2-glycoprotein I antibodies. Arthritis Rheum. 1999;42(11):2461-70.

24. Agostinis C, Durigutto P, Sblattero D, Borghi MO, Grossi C, Guida F, et al. A non-complement-fixing antibody to beta2 glycoprotein I as a novel therapy for antiphospholipid syndrome. Blood. 2014;123(22):3478-87.

25. von Landenberg C, Lackner KJ, von Landenberg P, Lang B, Schmitz G. Isolation and characterization of two human monoclonal anti-phospholipid IgG from patients with autoimmune disease. J Autoimmun. 1999;13(2):215-23.

26. Agostinis C, Biffi S, Garrovo C, Durigutto P, Lorenzon A, Bek A, et al. In vivo distribution of beta2 glycoprotein I under various pathophysiologic conditions. Blood. 2011;118(15):4231-8.

27. Vismara A, Meroni PL, Tincani A, Harris EN, Barcellini W, Brucato A, et al. Relationship between anti-cardiolipin and anti-endothelial cell antibodies in systemic lupus erythematosus. Clin Exp Immunol. 1988;74(2):247-53.

28. Conrad K, Schneider H, Ziemssen T, Talaska T, Reinhold D, Humbel RL, et al. A new line immunoassay for the multiparametric detection of antiganglioside autoantibodies in patients with autoimmune peripheral neuropathies. Ann NY Acad Sci. 2007;1109:256-64.

29. Devreese KM, Pierangeli SS, de Laat B, Tripodi A, Atsumi T, Ortel TL Subcommittee on Lupus Anticoagulant/Phospholipid/Dependent Antibodies. Testing for antiphospholipid antibodies with solid phase assays: guidance from the SSC of the ISTH. J Thromb Haemost. 2014;12(5):792-5.

30. Pengo V. ISTH guidelines on lupus anticoagulant testing. Thromb Res. 2012;130 Suppl 1:S76-7

31. Seifert M, Schoenherr G, Roggenbuck D, Marx U, von Baehr R. Generation and characterization of a human monoclonal IgM antibody that recognizes a conserved epitope shared by lipopolysaccharides of different gramnegative bacteria. Hybridoma. 1996;15(3):191-8.

32. Chabraoui F, Derrington EA, Mallie-Didier F, Confavreux C, Quincy C, Caudie C. Dot-blot immunodetection of antibodies against GM1 and 
other gangliosides on PVDF-P membranes. J Immunol Methods. 1993;165(2):225-30.

33. Schoenherr G, Roggenbuck D, Seifert M, Jahn S, Porstmann T. Technical problems arising from the use of the immunoblot for determination of the reactivity of natural antibodies with different lipopolysaccharides (LPS). J Immunol Methods. 1996;190(2):185-8.

34. Pelkmans L, Kelchtermans H, DE Groot PG, Zuily S, Regnault V, Wahl D, et al. Variability in exposure of epitope G40-R43 of domain i in commercial antibeta2-glycoprotein I lgG ELISAs. PLoS One. 2013;8(8), e71402.

35. de Laat B, DE Groot PG. Autoantibodies directed against domain I of beta2glycoprotein I. Curr Rheumatol Rep. 2011;13(1):70-6.

36. Andreoli L, Nalli C, Motta M, Norman GL, Shums Z, Encabo S, et al. Antibeta(2)-glycoprotein I lgG antibodies from 1-year-old healthy children born to mothers with systemic autoimmune diseases preferentially target domain 4/5: might it be the reason for their 'innocent' profile? Ann Rheum. Dis. 2011;70(2):380-3.

37. Pengo V, Ruffatti A, Tonello M, Hoxha A, Bison E, Denas G, et al. Antibodies to Domain 4/5 (Dm4/5) of beta2-Glycoprotein 1 (beta2GP1) in different antiphospholipid (aPL) antibody profiles. Thromb Res. 2015;131 (1):161-3.

38. Pengo V, Ruffatti A, Tonello M, Cuffaro S, Banzato A, Bison E, et al. Antiphospholipid syndrome: antibodies to Domain 1 of beta2-glycoprotein 1 correctly classify patients at risk. J Thromb Haemost. 2015;13(5):782-7.

\section{Submit your next manuscript to BioMed Central} and we will help you at every step:

- We accept pre-submission inquiries

- Our selector tool helps you to find the most relevant journal

- We provide round the clock customer support

- Convenient online submission

- Thorough peer review

- Inclusion in PubMed and all major indexing services

- Maximum visibility for your research

Submit your manuscript at www.biomedcentral.com/submit

) Biomed Central 